The 49th Annual Conference of the International Association of School Librarianship

The 24th International Forum on Research on School Librarianship

July 12 - 16, 2021

Vyacheslav Zavalin

Texas Woman's University

vzavalin@,twu.edu

\title{
Analysis of Genre and Subject Representation in the Children's and Young Adults' Cataloging Program (CYAC) Bibliographic Metadata for Fiction Books
}

\begin{abstract}
Bibliographic metadata that represents resources for children and young adults is important in providing access to these materials for school library users. In school library systems this bibliographic metadata exists in the form of records that are usually created in collaboration between publishers and cataloging agencies. Children's and Young Adults' Cataloging (CYAC) Program has been working at the Library of Congress since the 1960 s to provide services for school and public libraries. This paper reports analysis of genre and subject representation in bibliographic metadata for fiction books created by the CYAC program. This metadata is important for discovery and supports genrefication efforts.
\end{abstract}

Keywords: genrefication, fiction, metadata, school libraries, CYAC

\section{Introduction and Relevant Literature}

Fiction and non-fiction materials created for children are collected by school libraries. To make these materials easily findable not only on the physical shelves but also through search or browse, they are represented by bibliographic records in online catalogs. School media specialists are responsible for a variety of important tasks, and devoting efforts to original cataloging (creating new bibliographic records) is in most cases not feasible. Therefore, school libraries rely on other agencies to create metadata for their catalogs: library consortia, publishers and other vendors, etc. In the United States, the Library of Congress Children's and Young Adults' Cataloging (CYAC) Program formerly known as Annotated Card (AC) Program, has traditionally contributed bibliographic records representing resources of interest to audiences served by school libraries (Library of Congress, 2015). The program pays special attention to subject representation, particularly, Children's Subject Headings (CSH) and LCSH controlled vocabularies, LCC and DDC classification (Library of Congress, n.d.). Once part of the centralized online bibliographic database (e.g., WorldCat ${ }^{1}$ ), records become available for copy cataloging to any interested library. Some institutions adopt bibliographic records from centralized databases for their local catalogs without changes, others add value to these shared records by making edits. 
Subject access is well known as one of the main ways for users to access information. Access by genre is gaining more and more importance in recent years. This is especially true for school libraries, where physical fiction collections are being reorganized to improve browsing discovery by genre -- a process known as genrefication (Sultanik, 2020; Moeller \& Becnel, 2019). Genrefication is enabled through extension of genre representation in bibliographic records. High-quality bibliographic records such as those created by the US Library of Congress, are known to provide relatively thorough subject and genre representation (e.g., Hider \& Tan, 2008).

\section{Research Problem Statement}

Despite growing importance of genre and subject metadata for school libraries, to the end of our knowledge, no published studies examined genre and subject representation in bibliographic records representing school library materials. The project reported here aims to address this research need, with the focus on records produced by the CYAC program.

\section{Methodology}

WorldCat bibliographic records created by the CYAC program to represent fiction books in English language, as well as in major Western languages and most widely used non-Latin script languages were identified via OCLC Connexion Browser search. Search criteria included original cataloging agency code "DLC" in MARC field 040 subfield \$a, record creation date range between 2014 and 2020, and inclusion of authentication code "Icac" that identifies CYAC records in MARC field 042 subfield $\$$ a. The records that matched search criteria were then collected using MarcEdit Z39.50/SRU by record IDs. A total of 696 records were harvested. Record deduplication resulted in 688 unique records.

The data analysis used a combination of computational tools and data mining techniques and included examination of the following:

- Application of data elements representing genre (MARC field 655 and its subfields) and genre controlled vocabularies.

- Application of data elements representing subject (non-655 6XX MARC fields and subfields, classification fields etc.) and subject controlled vocabularies.

\section{Selected Findings and Discussion}

Overall level of application of genre headings was high: $96.8 \%$ of records included one or more instances of field 655, with an average of 6.3. Use of a total of 20 genre controlled vocabularies was observed: most widely used was FAST (51.18\% of field instances), followed by LCGFT (21.55\%), LCSH (9.33\%), and GSAFD (4.7\%). Most records (99.56\%) included call numbers based on the DDC classification system which is predominantly used in school library catalogs even as libraries are adopting genrefication over classification for physical arrangement (e.g., Moeller \& Becnel, 2019). LCC call numbers were also included in all but one record. In addition, $4.8 \%$ of records included classification numbers assigned in Canada, $0.58 \%$ included 
National Library of Medicine call numbers, and one record each included UDC call number or a Subject Category Code.

All but one record included the subject metadata field that applies in representing any resource: topical subject heading field 650, with an average of 12.02 instances. Eight additional subject representation fields of a less-general applicability were found in 1 or more records each. Use of a total of 18 subject controlled vocabularies was observed: most widely used was CSH (98.69\% of all records), followed by FAST (96.37\%), and LCSH (95.93\%). Almost 30\% of records included BISAC subject headings. Less than one-third of records were found to include Sears subject headings that school libraries commonly rely on for subject representation (e.g., Kelsey, 2014). CYAC program activities do not include assignment of Sears headings. However, it is surprising that in this dataset which largely comprises records created several years ago and edited multiple times by various institutions Sears headings were seldomly added.

\section{Implications and Conclusions}

Findings demonstrated that CYAC records, as amended by OCLC members in the WorldCat database, provide a thorough genre and subject representation through 10 metadata fields. Controlled vocabularies and classification schemes include but are not limited to CSH, LCSH, DDC and LCC prioritized by CYAC. Sears headings commonly found in school library metadata are not used at the expected level. Still, a number of various genre and subject controlled vocabularies are used to greater or lesser extent. This variety facilitates genre and subject access and indicates strong support to the needs of school library users. The CYAC program does not cover non-fiction. More research is needed to examine genre and subject content in bibliographic records that represent non-fiction literature for children and young adults. There is also a need for research into the ways and extent to which the user needs are supported by school library bibliographic metadata originating from CYAC project and other sources. Future studies should include interviews and/or observations of school library users: students and teachers.

\section{References}

Hider, P. \& Tan, K. (2008). Constructing record quality measures based on catalog use.

Cataloging \& Classification Quarterly 46(4), 338-361.

Kelsie, M. (2014). Cataloging for school librarians. Lanham: Rowman \& Littlefield.

Library of Congress. (2015). About the program: Children's and Young Adults' Cataloging

Program (CYAC). Retrieved January 24, 2021 from

https:/www.loc.gov/aba/cyac/about.html

Library of Congress. (n.d.). Subject cataloging: Children's and Young Adults' Cataloging

Program (CYAC). Retrieved January 24, 2021 from

https://www.loc.gov/aba/cyac/subject.html 
Moeller, R.A., \& Becnel, K.E. (2019). "Why on earth would we not genrefy the books?": A study of reader-interest classification in school libraries. Knowledge Organization, 46(3), 199-208.

Sultanik, A.G. (2020, July). Genrefying the children's fiction collection. School Library Research, 23, 1-23. 